To the Editors:

\title{
Reply: Takotsubo cardiomyopathy after an emotional outburst
}

\section{J Finsterer, M Frank}

Ceylon Medical Journal 2016; 61: 45-46 DOI: http://doi.org/10.4038/cmj.v61i1.8266

With interest we read the article by Shyamali et al. about a 63-year-old female with classical Takotsubo syndrome (TTS) after an emotional argument with her daughter-in-law [1]. We have the following comments.

Physical stress triggering TTS may not only be trauma, surgery, or severe illness, but also central nervous system disorders, such as subarachnoid bleeding, epilepsy, ischaemic stroke, intracerebral bleeding, posterior reversible encephalopathy syndrome (PRES), amyotrophic lateral sclerosis, bacterial, viral, or immune-mediated meningitis / encephalitis and traumatic brain or spinal cord injury. Rare causes of central nervous system triggers of TTS include hydrocephalus, subdural haematoma, venous aneurysm, brain tumour, hepatic encephalopathy and multiple sclerosis [2]. Though apical ballooning is the common abnormality in TTS, other parts of the left ventricular wall may be involved rarely [3]. The prognosis of TTS is usually good in the majority, but the outcome may be poor if the underlying trigger is a severe disorder, if the global type of TTS is present, or if TTS is complicated by severe rhythm abnormalities [4]. During treatment catecholamine should be avoided in TTS despite severe systolic dysfunction, since catecholamine storm is regarded as the principal pathogenetic factor of TTS [5].

Krankenanstalt Rudolfstiftung, Vienna, Austria.

Correspondence: JF, e-mail: <fifigs1@yahoo.de>. Received 17 November 2015.

Vol. 61, No. 1, March 2016 


\section{Conflicts of interests}

There are no conflicts of interest.

\section{References}

1. Shyamali NL, Ranawaka H. Takotsubo cardiomyopathy after an emotional outburst. Ceylon Med J 2015; 60: 113-4.

2. Finsterer J, Stöllberger C. Neurological and non-neurological triggers of Takotsubo syndrome in the pediatric population. Int J Cardiol 2015; 179: 345-7.
3. Wang Y, Xia L, Shen X, et al. A New Insight Into Sudden Cardiac Death in Young People: A Systematic Review of Cases of Takotsubo Cardiomyopathy. Medicine (Baltimore) 2015; 94: e1174. doi: 10.1097/ MD.0000000000001174.

4. Templin C, Ghadri JR, Diekmann J, et al. Clinical Features and Outcomes Takotsubo (Stress) Cardiomyopathy. N Engl J Med 2015; 373: 929-38.

5. Mugnai G, Pasqualin G, Prati D, Menegatti G, Vassanelli C. Recurrent multiform Takotsubo cardiomyopathy in a patient with epilepsy: Broken heart or brain? Int J Cardiol 2014; 201: 332-5. 